\title{
Development of an educational programme to support registered nurses during clinical supervision of student nurses in medical and surgical wards in a training health facility, in the oshana region, Namibia
}

\author{
Hanna Neshuku*, Amukugo Hans Justus \\ Lecturers, School of nursing, Faculty of health Sciences University of Namibia \\ *Corresponding author E-mail: hneshuku@unam.na
}

\begin{abstract}
This paper describes the processes of developing an educational programme intervention which was carried out following three phases namely:

Phase (1) one situation analysis which was carried out to explore and describe the lived experiences of registered nurses and student nurses regarding the clinical supervision of student nurses in medical and surgical wards. Phase 2 was about conceptualization, and of the frame work to guide the development of an educational programme to support registered nurses during the clinical supervision of student nurses. Phase 3 was about the development of an educational programme to support registered nurses during clinical supervision of student nurses.

The development of the conceptual framework, which led to the development of the programme to support registered nurses during the clinical supervision of student nurses, proves that this study makes an original contribution to the body of knowledge.
\end{abstract}

Keywords: Development; Challenges; Conceptual Framework; Educational Programme.

\section{Introduction}

The purpose of this study was to develop, implement and evaluate an educational programme to support registered nurses in clinical supervision of student nurses in medical and surgical wards of training health facilities in the Oshana region in Namibia. Namibia is located in the south-western part of the African continent and shares borders with Angola and Zambia in the north, with Botswana in the east, and with South Africa in the south and south east. It has a surface area of $824,295 \mathrm{~km}^{2}$ and ranks as Africa's fifteenth largest country Ministry of Health and Social services (MOHSS, 2004).

Clinical supervision is the term used to describe an educational relationship between an experienced nurse and nursing students (A Dictionary of Nursing, 2008). Clinical supervision of nursing students in Namibia takes place in the health facilities which were approved by the Health Professionals Council of Namibia as training health facilities. Todd and O'Connor (2005) refer to clinical supervision as the cornerstone of clinical practice. Hlongwa (2003) holds the opinion that it is through the mode of clinical practice that nursing students are provided with the opportunity to translate theoretical knowledge into practice. The aim of learning in clinical practice is to enable student nurses to develop in the domains of competence and to become safe, caring and competent decision-makers (Preceptorship, 2003).

Professional nursing is a practice-based discipline built upon nursing knowledge and theory. Therefore, these healthcare facilities are the laboratories where the complex processes of art and sci- ence of nursing are learned. It is in the "laboratory" of the health facilities where student nurses are supervised by experienced nurses whom are registered nurses who work in the clinical area as well as lecturers from the educational institution, to diagnose and treat human responses to actual and potential problems. Clinical practice has been an integral part of nursing education. Sharif and Masoumi (2005) hold the opinion that clinical practice prepares student nurses to be able to master the art of "doing" as well as "knowing" the clinical principles in practice. It further stimulates students to use their critical thinking skills for problem solving. Both education and service institutions share in the creation of a supportive learning milieu. To master the discipline of nursing and the increasingly complex skills required to deliver safe and effective patient care, both theoretical and clinical practices are essential for nursing students (American Association of Colleges of Nursing, 2011).

For the purpose of this study, the researcher concentrated on clinical supervision in the medical and surgical wards of training hospitals in Oshana region, Namibia only. It is therefore in the milieu of the medical and surgical wards where the researcher would like students to, as stated by McCarty and Higgins (2003) develop the ability to critically analyze and solve clinical problems which are fundamental characteristics of nurse education. It is only through effective clinical supervision that a meaningful correlation of theory and practice can occur, a view supported by Hlongwa (2003) as well as Sharif and Masoumi (2005), who bring all ends together to meet the essential; that the fundament of clinical supervision in practice is nursing education. 
Beside the physical environment or milieu in which supervision occurs, role functions and organizational frameworks also play a fundamental role. Those role functions refer to feelings of safety, security, self-awareness and self-confidence as well as meanings attached to the role of the supervisor and that of the student, while framework refers to clear roles and responsibilities through the provision of clinical practice guidelines.

If there is a gap between theory and practice in nursing education of student nurses, the ability to develop understanding and professional knowledge that stems from both theory and practice will be affected. Addis and Karadag (2003) as well as Papp, Markkanen and Von Bonsdorff (2003) are of the opinion that a very important contribution to clinical supervision is to increase students knowledge and their capability to synthesize theoretical knowledge with nursing care.

The integration of theory and practice has didactics at its centre. It requires that supervisors, namely registered nurses, have in-depth knowledge of the subject matter as well as a broad knowledge of the disciplines that are taught. Not only should supervisors have sound knowledge of the subject that they teach or the discipline where they supervise student nurses in clinical practice, but they should also be able to demonstrate a link between the theoretical knowledge from various study units, so that students can see the whole "gestalt," the picture of how everything that they have learned in the classroom fits into the clinical milieu (Henderson, n.d., para.7). To ensure effective facilitation of teaching and assessment of learning, the minimum educational requirement at the University of Namibia (UNAM): Faculty of Health Science (FHS) is that lecturers should hold at least a Master degree in Nursing Science means that lecturers need to have higher knowledge in nursing and capability to synthesize theoretical knowledge with nursing care needed in clinical supervision...

Supervision has to occur in an organized way. The registered nurses who supervise student nurses start with the orientation of the learners/students in a specific area. It is through orientation that students become acquainted with the new environment. At the time of orientation, clinical objectives, assessment information and other didactic factors are introduced. Carlson, Kotze and Van Rooyen (2003) state that the main function of an orientation programme is to reduce fear and uncertainties; therefore, proper orientation is essential to help students to cope and start learning with less or without fear and being certain on what is expected from them. Furthermore, orientation should include the integration of students into the practice system as well as the healthcare team. The supervisor's role includes tasks such as demonstrating nursing skills and problem-solving skills on issues related to clinical practice. The application of the nursing process in providing nursing care is of particular importance when it comes to problem-solving. Another important function that the registered nurse has is to directly guide the students through difficult cognitive information towards understanding thereof by application of it in clinical practice. Equally important is the supervision of therapeutic communication techniques to facilitate collaboration with clients and their families (An Bord Alstranais, 2003).

The registered nurse should be the mirror of professional conduct to students. Dale, Leland and Dale (2013) view clinical supervision as an important aspect that can be used to facilitate ethical development so that students can be encouraged to reflect on their experiences related to handling ethical issues in clinical settings. Student nurses acquire the knowledge, skills and values necessary for professional practice through clinical supervision. It is only in a safe and secure environment that students can develop selfawareness and self-confidence. Sardo, Santos Kock Pires Machado and Morais (n.d., p. 1) (a) are of the opinion that students get the opportunity to work in a clinical area in which knowledge is created, tested, applied, monitored and evaluated.

The environment in which students and the registered nurse meet for an educational encounter should be conducive to learning. The environment has to be openly supportive of student nurses' independence and freedom to learn and experiment. However, a conducive and supportive learning environment depends on the avail- ability of support systems. Such support systems include supervision, a conducive and supportive learning environment, and a good relationship between the faculties, registered nurses in the clinical area and student nurses (Begat \& Serevinsson, 2005).

Authors such as Addis and Karadag 2003) and Astron\& Moassiotis (2003), report a decrease in the learning opportunities that result from the increase in the number of clients/patients. Registered nurses might find it difficult to balance the time available to supervise students. Moeti, van Niekerk \&Van Velden (2004), share similar views that workloads and shortages of staff resultantly limit the opportunities for effective teaching and supervision of students while in clinical settings. The factors under discussion might mean that students' expectations of their clinical learning objectives are not met. It was evident from the study done by lipinge and Venter (2003) that unmet expectations in the clinical setting resulted in frustrations that related to poor theory and practice integration as well as lack of tutorial support and guidance by registered nurses.

\subsection{Problem statement}

Background information highlighted the unmet need of student nurses and registered nurses during clinical supervision. Therefore, it is unclear whether clinical supervision of student nurses in training health facilities in the Oshana region in Namibia is effective. Furthermore, it is not known whether registered nurses have the necessary knowledge and skills on how to supervise student nurses. Since the implementation of the Diploma in Comprehensive Nursing and Midwifery Science at the University of Namibia, 537 students have successfully completed the diploma. The Bachelor of Nursing Science (Clinical) degree was introduced in 2008, and the diploma was phased out in 2010. If clinical supervision was not done effectively, then the training and education of 537 registered nurses who currently work in the clinical field of nursing is questionable, and it will continue to be the same with those who are going to complete their Bachelor's Degree in Nursing Science. Therefore, the standard of clinical practice with regards to quality and quantity caught planners and supervisors of clinical practice off guard.

On the other hand, some supervisors complain that student nurses are seen sitting at the nurses' station during working hours and not taking part in what is taking place in the wards. This situation put a question mark on the supervision of student nurses while they are at clinical practice.

The supernumerary status of students brought some challenges to the arena of clinical supervision. This factor unfortunately resulted in absenteeism of students from clinical practice because some of them feel that they are not full members of the staff at service. This situation makes it difficult for the supervisors who are supervising them. This situation is not unique to Namibia only. O'Cauaghaint and Slevin (2003) in their study report of an investigation of the lived experiences of registered nurses facilitating supernumery nursing student nurses who student behavior and absenteeism merely add to the ever-present challenges need to be overcome in order to meet educational requirements. These concerns have triggered the interest in the researcher to explore and describe the lived experiences of student nurses and registered nurses in clinical supervision. Research questions are queries that are asked and their answers facilitate the achievement of the study objectives (Cohen, Manion \& Morrison, 2007).

The problem statement stated above prompted the researcher to formulate the following research questions:

- How do student nurses and registered nurses in medical and surgical wards in training hospitals in Oshana region, Namibia experience clinical supervision?

- What can be done to facilitate effective clinical supervision of student nurses by registered nurses in medical and surgical wards in training hospitals of Oshana region? 


\subsection{Purpose of the study}

The purpose of the study was to develop, implement and evaluate an educational programme to support registered nurses during clinical supervision of student nurses in the medical and surgical wards of the training hospitals of Oshana region in Namibia.

\subsection{Objectives of the study}

In order to answer the research questions, the objectives of the study were to:

- explore and describe the lived experiences of student nurses and registered nurses regarding clinical supervision in the medical and surgical wards in training heath facilities of Oshana region in Namibia

- conceptualize the results forthcoming from the first objective in order to develop a framework for development of an educational programme to support registered nurses during clinical supervision of student nurse in medical and surgical wards in training heath facilities of Oshana region in Namibia

- develop an educational programme to support registered nurses during clinical supervision of student in medical and surgical wards of training heath facilities of Oshana region in $\mathrm{Na}-$ mibia

- implement and evaluate an educational programme to support registered nurses during clinical supervision of student nurses in medical and surgical wards of training heath facilities of Oshana region in Namibia

\subsection{Paradigmatic perspectives}

Qualitative researchers approach studies with a certain paradigm or worldview, a basic set of beliefs or assumptions that guide their inquiries (Polit, Beck \& Hungler 2006). Inquiries (Polit \& Beck 2009) define paradigm as a phenomenon that encompasses a set of philosophical assumptions and that guides one's approach to inquiry. Four types of assumptions were applied to this study. These assumptions are related to the ontological assumption or the nature of reality, the epistemological assumption or the relationship of the researcher to that being researched, the axiological assumption or the role of values in a study and the methodological assumptions or the process of the research study. According to Shuttleworth (2008), paradigm is a framework containing the assumptions on the research subject, research structures and research methods on how the research should be carried out. It is the whole system of thinking, a basic orientation to research and theory; the window through which the researcher views the world.

Rew(2005) describes a paradigm as the researcher's own view of concepts; thus the theory about theory. Paradigms therefore influence the identification of researchable problems, the most relevant methods, as well as the appropriate techniques by which data is collected, analysed and interpreted. It is acknowledged that researchers have different paradigms, views and understanding in terms of issues they are researching.

In order to clarify the researcher's understanding of the concepts related to the research and the implications thereof, the philosophical assumptions for this study were as follows:

\subsection{Theoretical basis of the study}

The researcher chooses Kolb's (2001) theory of experiential learning, Adult learning theory according to Knowles (in Atherton, 2002, p. 12 and Dickoff, James and Wiedenbach's (1968) practice theory as theoretical perspectives of this study.

- Dickoff, James and Wiedenbach's (1968) practice theory This theory was used to conceptualize the findings of the study as well as the resources that address the needs of the registered nurses and the students. The theory prescribed the activities or interventions required to reach pre-determined goals and predict the consequences of interventions. It outlines the goal to be achieved, surveying alternatives and prescribing activities to attain the goal (Dickoff, James and Wiedenbach, 1968; McEwen \& Wills, 2011). The theory outlines six questions, which explain concepts and analyze the prescribed activities that are aimed at realizing the programme goal, namely: - Who or what perform activities?; Who or what is the recipient of the activity?; In what context is the activity performed?; What is the end product of the activity?; What is the guiding procedure technique of protocol of the activity? What are energy sources for the activity?

- Kolb's theory of experiential learning:

Kolb's theory of experiential learning was the guiding procedure and technique when the educational programme was implemented.Kolb sees learning as a core process of human development and makes a distinction between development and readjustment. Development results from learning that is gained through experience, and this is the basis of the theory (Quinn \& Heights, 2007).The four stages cycle consists of:

- Concrete experience - (doing/having an experience) this is learning from discussions and feedback from fellow participants.

- Reflective observation - (reviewing and reflecting on experience) - this involves observation of others or to develop observation on own experience that will be made possible through brainstorming or reflective exercises like role plays.

- Abstract conceptualization - (concluding / learning from experience) - this is learning from authority, directed learning situations that emphasize theory; for example learning from lecture presentations and make own conclusion.

- Active experimentation - (planning and trying out what was learned) - it includes active learning through experimentation; for example, learners when engaged in small-group discussions, learning from case studies, homework or simulations.

The four definitions of the learning styles (each representing the combinations of two preferred styles) consist of:

- Diverging - this includes (concrete and reflective) feeling and watching, gathering information and viewing concrete situations from many or different perspectives, adopt by observation rather than actions which can be made possible by brainstorming

- Assimilation - (abstract reflective) pulls a number of ideas or observations into an integrated whole, for example through lecture presentations.

- Converging - practical application of ideas and problem solving, for example during case study role plays

- Accommodation - (learn by trying) tries different ways to achieve objectives

Kolb's cycle begins with concrete experience, whereby registered nurses get a chance to reflect on their experiences and analyze them until insight begins to emerge. The implications arising from this conceptualization can then be utilized to modify existing practices in providing supervision of students (Willis \& Ricketts, 2004).

- Adult learning theory:

According to (Atherton, 2002) two key differences in the ways that adults and children approach learning are that adults desire to be self-directed and want to take responsibility for decisions. Courses for adult learners are sensitive to these desires and designed to permit some autonomy in how participants approach and schedule their learning activities. Knowles' lists the following assumptions on adult learning: adults need to know why they need to learn something; adults need to learn experientially; adults approach learning as problem-solving and adults learn best when (they believe that) the topic is of immediate value.

Based on the assumptions of adult learning listed above the facilitator made use of teaching strategies, such as role play (autonomy, experience) group work, feedback and self-evaluation during the implementation of the programme in chapter 6 of this study to ensure active participation and effectiveness of the programme (Kobus, 2007). 


\subsection{Measures to ensure trustworthiness}

The researcher adhered to the principles of trustworthiness throughout the research process. Trustworthiness is a method of ensuring rigor in qualitative research (Brink, 2007). Polit and Beck (2009) are of the opinion that research findings should be as trustworthy as possible and every research study must be evaluated in relation to the procedures used to generate the findings.

Measures for trustworthiness were ensured for this study by using the following four criteria: credibility, dependability, transferability and the confirmability method of trustworthiness ((Macnee \& McCabe, 2008). and will be discussed in fully in chapter 2 of this study.

\subsection{Ethical measures}

Ethical measures that were considered in this study included obtaining written permission from the Research Postgraduate committee of the University of Namibia as well as from the Ministry of Health and Social Services, to conduct the research. Verbal informed consents were requested and obtained from the participants to take part in the study and their participation was voluntary.

\section{Methodology}

The development of the educational programme was carried out in four phases, namely situation analysis, development of the conceptual framework, programme development, programme implementation and evaluation.

\subsection{Phase 1: situation analysis}

The research design for this study was qualitative, descriptive, explorative and contextual in nature, which explored and described the lived experiences of student nurses and registered nurses regarding clinical supervision of student nurses. Qualitative design was used for this study in order for the researcher to explore and describe experiences of student nurses and registered nurses regarding clinical supervision of student nurses in training health facility in Oshana region, Namibia It was found appropriate to use qualitative research design because issues with regard to clinical supervision in clinical setting where student nurses are supervised by registered nurses in order to understand how a particular phenomenon was being dealt with ( Burns \&Grove 2009). Explorative design was used in order to establish and gather new fact regarding clinical supervision of student nurses on order to determine whether there were new information that will lead to that the researcher is gain new insight into the phenomenon under study (Babbie \& Mouton 2009). Descriptive design allowed the researcher to obtain accurate and complete information about the experiences of student nurses and registered nurses regarding clinical supervision of student nurses in training health facility in Oshana. This was done through conduction of individual face to face interviews. The contextual interest of the researcher was aimed at the understanding of clinical supervision of student nurses ion the natural setting which is medical and surgical wards of training health facility in Oshana region, Namibia (Babbie \& Mouton 2009

The population were all the students who were enrolled for the Comprehensive Diploma in Nursing and Midwifery Science and Bachelor's Degree in Nursing Science at the University of Namibia as well as registered nurses who were supervising the clinical learning of nursing students of the above-mentioned programme in the medical surgical wards at the Oshakati Intermediate training Hospital in the Oshana Region.

A purposive sampling and criterion sampling method were used to select the participants. The inclusion criteria for the study were that the second and third-year student nurses were selected to participate in the study hoping that because they have been in clinical settings under supervision for two to three years, they will be in such a condition that they will be able to provide valid information on their experiences about clinical supervision rather than firstyear student nurses. On the other hand, the fourth-year student nurses were not selected with the reason that the researcher has an assumption that they have already started to develop coping mechanisms to the situations encountered during their supervision. The registered nurses were selected on the basis of their involvement with clinical supervision of second and third year students in medical and surgical wards and those on day duty only because student nurses are working day duties only.

Total number of student ofthirty (30) student nursesten(10) from each level as well as eight (8) registered nursesparticipated in the study. The sample size was determined by data saturation (Holliday, 2003). Methods of data collection were individual in-depth face to face interviews and field note. Individual in-depth face to face interviews were conducted with registered nurses and students and two major questions which were asked are:

- "How do you experience clinical supervision of student nurses?"[ register nurses]

- "How do you experience clinical supervision offered by registered nurses?" [ student nurses], Follow-up questions were asked as need arise for clarification as well as for more information

Tape record was used to capture all responses from the participant and field notes were taken to record non-verbal observation.data transcription and data reduction were followed while analyzing the data. Topic were listed then re-organized and rearranged into subthemes and then themes (Saks \& Allsop, 2007; Kobus, 2007; De Vos et al., 2007; Creswell (2008) .Three (3) themes, made up out of eleven (11) sub themes were identified as followed. The first themes focuses on nurses and student nurses experiences managerial challenges during clinical supervision of student nurses by registered nurses in medical and surgical wards of training health facility in Oshana Region, Namibia. The second one focuses experience non-conducive environment during clinical supervision of student nurses by registered nurses in medical and surgical ward. And the last one focuses on the training facilities. See table 1.

\subsection{Phase 2: development of the conceptual framework}

Phase2: aimed at conceptualization of the results forthcoming from phase 1 in order to develop a framework which guided the development of an educational programme to support registered nurses during clinical supervision of student nurse in medical and surgical wards in training heath facility of Oshana region in $\mathrm{Na}-$ mibia. Concepts were classified according Dickoff, James and Wiedenbach's (1868) survey list agent, recipient, context, procedure, dynamics and terminus as appeared in the figureel next page:

The researcher's reasoning map represents the interaction between the agent and recipients, which is contextualized within a specific framework and procedure. The use of reasoning maps is a powerful and useful approach for modelling knowledge and qualitative reasoning. Thus, a reasoning map is a structure of concepts for a specific domain (Alejandro, Humberto \& Agustin, 2005).

The researcher's thinking map represents the interaction and facilitation between the agent and the recipient, which is conceptualized within a specific framework whilst acknowledging the dynamics underpinning the interaction and the facilitation process. Both the context and the dynamics determined the procedures to be followed towards the goal attainment of a desired outcome. The terminus (outcome) is the effect of the procedure on the recipient and context towards the dynamic.

The survey list is the identification and categorization of major and related concepts of activity prescription namely the agent, recipient, context, terminus procedure and dynamics (Dickoff James \&Wiedenbach, 1964). In this study, the major concepts are placed in a relational order of casual-connection, thus ensuring a logical development and implementation of an educational programme, containing prescribed activities in order to achieve the 
goals suggested by the survey list. The next table illustratePhase 2: Developmental of the conceptual framework.

\subsection{Phases 3 programme development}

The programme development constituted phase 3 of this study and was based on the survey guide suggested by Dickoff et al., (1968). The researcher was guided by the six survey ingredients as was stipulated in chapter 4 . The programme was also developed in line with the educational expectation that a programme should have a specific focus, based on the need assessment outcome or findings, which is a crucial fact in programme development. The need assessment done during phase 1 (situation analysis) provided a foundation for the development of this educational programme. The programme developed contained the purpose and goals of the programme, programme objectives, programme structure, participant's role and responsibilities, activities, processes and approaches. All described fully in chapter 3 of this study. The next table illustrate Phase 3: Programme development

\subsection{Phases 4 programme implementation and evaluation}

Programme implementation involves putting the programme which was developed into effect, in other words executing the planned activities of the programme (Lundy \& Janes, 2009). To achieve the effectiveness of the programme implementation, its goal and objectives, it is imperative to select an appropriate teaching methodology. For the implementation of an educational programme and to support registered nurses during their clinical supervision, the researcher selected to conduct a workshop with the reason that during the workshop, it is possible to have a two-way communication whereby ideas and facts are exchanged with the aim to get valued information from both sides. The programme had a time frame which set the date and time when to start with the workshop (the selected method of programme implementation) and for how long will it last. For this study, the duration of the workshop was two days. It also consisted of the work plan for implementation, which was drawn up providing the guideline on what is to be implemented, when, by whom and how it should be implemented (Watson, 2011). The programme was implemented in three phases. Phase one was the introductory phase, the working phase which in turn consisted of three sessions and lastly phase three was the termination phase. The researcher kept detailed field notes, including the observational notes throughout the course of implementing the programme. The implementation of each session was implemented based on the specific objective activities of that session and it was expected to produce an outcome that will help the registered nurses during the execution of their duty of clinical supervision of student nurses. The implementation of each session was evaluated by the participants and the evaluation of the workshop was done at the end the workshop. The post evaluation of the feasibility of the programme was done two months after the implementation. Table 1illustrate below. Phase 4: Programme implementation and evaluation.

\section{Results}

\subsection{Phase 1: experiences of student nurses and registered nurses}

Objective one was to explore and describe the lived experiences of student nurses and registered nurses regarding clinical supervision in the medical and surgical wards in training heath facilities of Oshana region in Namibia. Three (3) themes and ten (10) sub themes. These were basis in which the educational programme developed.

Table 1: Themes and Sub Themes

\begin{tabular}{|c|c|}
\hline Themes & Sub themes \\
\hline \multirow{4}{*}{$\begin{array}{l}\text { 1. managerial chal- } \\
\text { lenges }\end{array}$} & Too much workload and shortage of staff \\
\hline & Lopsided supervisor student ratio \\
\hline & No clinical instructors \\
\hline & Lack of knowledge on supervision role \\
\hline \multirow{4}{*}{$\begin{array}{l}\text { 2. Educational chal- } \\
\text { lenges }\end{array}$} & Gap between theory and practice \\
\hline & Out-dated supervisors \\
\hline & $\begin{array}{l}\text { Supervisors providing ineffective clinical su- } \\
\text { pervision }\end{array}$ \\
\hline & Poor guidance of students about supervisors \\
\hline \multirow[t]{2}{*}{$\begin{array}{l}\text { 3. Environmental } \\
\text { challenges }\end{array}$} & $\begin{array}{l}\text { Poor interpersonal relationship and communica- } \\
\text { tion between and among supervisors and stu- } \\
\text { dent nurses }\end{array}$ \\
\hline & Hospital stock shortage \\
\hline
\end{tabular}

\subsection{Phase 2: conceptualized results from objective one}

Conceptualize the results forthcoming from the first objective in order to develop a framework for development of an educational programme to support registered nurses during clinical supervision of student nurse in medical and surgical wards in training heath facilities of Oshana region in Namibia

Table 2: Illustration of Phase (2) Two: Developmental of the Conceptual Framework

Phase 2: Developmental of the conceptual framework

Activities OUTCOME

- Agent : Researcher as facilitator

- Recipient: Registered nurses in medical and surgical wards in training health facility Oshana region

- Context -: Medical and surgical wards in training health

2.1 Conceptual framework was developed based on the results of phase one. The survey list of Dickoff et all 1968 which includes the context, agent, recipient, dynamics, procedure and terminus serves as basis of the formulation of the conceptual framework development. facility Oshana region Namibia ,

- Dynamics: challenges regarding, managerial, educational and non-conducive environmental identified during situational analysis

- Procedure : development of an educational programme to address managerial educational and environmental challenges identified during situational analysis

- Terminus: Competent, confident registered nursesto provide effective clinical supervision of student nurses.

3.3. Phase (3) three: development an educational programme to support registered nurses during clinical supervision of student in medical and surgical wards of training heath facilities of oshana region in Namibia

Table 3: Illustration of Phase 3: Programme Development

\begin{tabular}{llll}
\hline Phase 3: Programme development & \\
\hline $\begin{array}{l}\text { Phase 3: Programme } \\
\text { development }\end{array}$ & Processes of programme development & Activities \\
$\begin{array}{l}\text { An educational pro- } \\
\text { gramme to facilitate }\end{array}$ & $\bullet \quad$ Programme objectives & $\bullet$ & To address managerial challenges \\
$\begin{array}{l}\text { clinical supervision of } \\
\text { students was developed }\end{array}$ & $\bullet \quad$ Programme structures & $\bullet$ & Under the following sub themes \\
$\begin{array}{l}\text { based on the results of } \\
\text { phase 1 and 2 and it was }\end{array}$ & $\bullet \quad$ Programme approaches & $\bullet \quad$ Managerial challenges & Educational programme \\
\end{tabular}




\begin{tabular}{lll}
\hline $\begin{array}{l}\text { based on experiential } \\
\text { learning by Kolb and } \\
\text { adult learning theory. }\end{array}$ & $\bullet$ No clinical instructors \\
& $\bullet$ Educational challenges \\
& $\bullet$ Gap between theory and practice \\
& $\bullet \quad$ Out-dated supervisors \\
& $\bullet$ Supervisors providing ineffective clinical \\
& $\bullet \quad$ Eupervision \\
& $\bullet \quad$ Poor guidance of students about supervisors \\
& $\bullet \quad$ Poor interpersonal relationship and commu- \\
& nication between and among supervisors and \\
& student nurses \\
\hline
\end{tabular}

3.4. Phase 4: programme implementation and evaluation implement and evaluate an educational programme to support registered nurses during clinical supervision of student nurses in medical and surgical wards of training heath facilities of oshana region in Namibia

Table 4: Illustration of Phase 4: Programme Implementation and Evaluation

\begin{tabular}{|c|c|c|c|c|}
\hline $\begin{array}{l}\text { Phase 4: Programme implemen- } \\
\text { tation and evaluation }\end{array}$ & Population & $\begin{array}{l}\text { Sampling and sample } \\
\text { size }\end{array}$ & Activities & Outcome \\
\hline $\begin{array}{l}\text { Programme implementation was } \\
\text { done based on Kolb experiential } \\
\text { learning and adult learning. } \\
\text { Sessions and workshop evalua- } \\
\text { tion was done during the pro- } \\
\text { gramme implementation. } \\
\text { Post workshop evaluation was } \\
\text { done two months after the im- } \\
\text { plementation to evaluate the } \\
\text { feasibility of the programme }\end{array}$ & $\begin{array}{l}\text { Registered nurses who } \\
\text { are supervising student } \\
\text { nurses and student } \\
\text { nurses }\end{array}$ & $\begin{array}{l}\text { No sampling was } \\
\text { done; all registered } \\
\text { nurses working in } \\
\text { medical and surgical } \\
\text { wards were invited. } \\
\text { The sample was all } \\
\text { registered nurses who } \\
\text { turned up to attend } \\
\text { the workshop. }\end{array}$ & $\begin{array}{l}\text { The following were car- } \\
\text { ried out awareness rais- } \\
\text { ing, group discussions } \\
\text { and plenary feedbacks as } \\
\text { well as case scenarios in } \\
\text { order to : Address the } \\
\text { managerial challenges , } \\
\text { educational challenges } \\
\text { and non-conducive envi- } \\
\text { ronment experienced by } \\
\text { student nurses and regis- } \\
\text { tered nurses during clini- } \\
\text { cal supervision of student } \\
\text { nurses in order to support } \\
\text { registered nurses during } \\
\text { clinical supervision of } \\
\text { student nurses }\end{array}$ & $\begin{array}{l}\text { Recommendations on the pro- } \\
\text { gramme itself and its implementa- } \\
\text { tion }\end{array}$ \\
\hline
\end{tabular}

\section{Conclusion}

This study is an original contribution to the body of knowledge on clinical supervision. The themes that were developed based on the findings after the analysis and interpretation as well as, the development of the conceptual framework, which led to the development of the programme to support registered nurses during the clinical supervision of student nurses, proves that this study makes an original contribution to the body of knowledge in general nursing science. The basic goal, namely the development, implementation and evaluation of the educational programme were achieved. This study made it possible for registered nurses to receive the much-needed information pertaining to the clinical supervision of student nurses, and served as a and will continue to be a guide and support tool for registered nurses while executing their role of clinical supervision of student nurses.

\section{Acknowledgment}

The University of Namibia (UNAM) and Ministry of Health and Social Services, Namibia are gratefully acknowledged for granted me the permission for this kind of professional discourses.

The hospital management for the Oshakati Intermediate Hospital for creating conducive environment enable me to conduct this study as well as for any kind of support offered to me during this study.

Special acknowledgement is accorded to all registered nurses and nursing students who had taken part in this study, for their contributions and co-operation that made this study possible.

\section{References}

[1] A dictionary of nursing. (2008). Clinical supervision. Retrieved from: http:www: encyclopaedia. com.doc/1062/clinical supervision html.

[2] Addis, G. \& Karadag, A. (2003).An evaluation of nurses' clinical teaching role in Turkey.Nurses Education Today, 23, 27-33. http://dx.doi.org/10.1016/S0260-6917(02)00159-4.

[3] Alejandro, P., Humberto. J., Agustin, G.D. (2005, October). Knowledge and Reasoning Supported by cognitive Maps.MICA 4150.

[4] American Association of College of Nursing, (2011). American Association of College of Nursing faculty shortage fact sheet Retrieved 2.6.2014, from http//www.aacnnche/mediarealtioNrsgShortageFS pdf.

[5] An Bord Alstranais. (2003).Guidelines on the key points that may be considered when developing a quality clinical environment.Retrieved from http:/www.nursingbord.ie.publication.

[6] Aston, L. \& Moassiotis, A. (2003).Supervising and supporting student nurses in clinical placements; the peer-support initiative.Nurse Education Today, 23, 202-210. http://dx.doi.org/10.1016/S02606917(02)00215-0.

[7] Atherton, J.S. (2002.) Learning and from experience. Retrieved 28 September 2009 at: http://www.dmu.ac.uk.

[8] Babbie, E. \& Mouton, J. (2009).The practice of social research $\left(9^{\text {th }}\right.$ ed.). Belmont. Wadsworth.

[9] Begat, I. \& Serevinsson, E. (2005).Nurses' satisfaction with their work environment and the outcome of clinical nursing supervision on nurses 'experience of well-being.Journal of Nursing Management, 13, 221-223. http://dx.doi.org/10.1111/j.1365-2834.2004.00527.x.

[10]Burns, N. \& Grove, S.K. (2009) the practice of nursing research. Philadelphia: W.B.

[11]Carlson, S., Kotze, W.J. \& Van Rooyen, D. (2003). Accompaniment needs of first year nursing students in the clinical learning environment. Curationis26 (2): 30-39.

[12]Cohen, L., Manion, L. \& Morrison, K. (2007).Research methods in education $\left(5^{\text {th }} \mathrm{Ed}\right.$.). London: Routledge. 
[13]Creswell.J.W. (2008). Educational Research: Planning, Conducting and Evaluating Qualitative \& Quantitative research. Pearson Education: New Jersey.

[14]Dale, B., Leland, A. \& Dale, J.D. (2013). What factors facilitate Good learning experiences in clinical studies in nursing Bachelor Student's Perceptions.Retrieved http:/www.hindawi.com/journal/isrn/2013/626879.

[15]Davhana-Maselesele, M. (2000).Problems in integration theory with practice in selected clinical nursing situations. Unpublished master's dissertation Pretoria University of South Africa.

[16]De Vos, A.S., Strydom, H., Fouche, C.B. \& Delport, C.S.L. (2007).Research at grassroots for Social sciences and human service professions. Pretoria: Van Schaik.

[17]Dickoff, J., James, A. \& Wiedenback. (1968). Theory in a practice discipline. Part 1; practice oriented theory. Nursing Research17 (5), 415- 435. http://dx.doi.org/10.1097/00006199-196809000-00006.

[18]Henderson, S. (undated). Clinical teaching involves more than evaluating students. Retrieved July 7, 2008 at http://1sn.curtin.edu.au/tlf/tlf1995/henderson.html.

[19]Hlongwa, E. (2003). .Diplomate's perceptions of their psychiatric nursing component of the four-year comprehensive programme. Retrieved July 17, 2008 from http://www.etd.unisa.ac.za/.

[20]Hodges, B.C. \& Vitedo, D.M. (2010).Assessment and planning in health programs $\left(2^{\text {nd }}\right.$ ed.). Sudbury: Jones \&Barlett.

[21]Holliday, A. (2003). Doing and Writing: Qualitative Research. SAGE Publications: London, Thousand Oaks.

[22] lipinge, S.N. \& Venter, E.S. (2003).Student nurses' experiences during rural Informal Education.Social Sciences method. 41. Thousand Oaks: Sage.

[23]Kobus, M. (2007).First steps in research. Van Schaik Publishers: Pretoria. SA.

[24]Kolb, A. \& Kolb, D.A. (2001).Experiential Learning Theory Bibliog raphy. New Jersey: Prentice Hall.

[25]Lundy, K.S. \& Janes, S. (2009). Community Health Nursing: caring for the public's health ( $2^{\text {nd }} \mathrm{ed}$.). Sudbury: Jones \& Bartlett.

[26] Macnee, C.L. \& McCabe, S. (2008). Understanding nursing research: Using research in evidence Practice ( $2^{\text {nd }}$ ed.). Philadelphia: Lippincott Williams \& Wilkins.

[27].McCarty, M. \& Higgins, A. (2003).Moving to an all graduate profession preparing preceptors for their role.Nurse Education Today, 9-95. http://dx.doi.org/10.1016/s0260-6917(02)00187-9.

[28] McEwen, M. \& Wills M. (2011). Theoretical bases for nursing ( $3^{\text {rd }}$ ed.). Philadelphia: Lippincott Williams \& Wilkins.

[29]Moeti, M.R., Van Niekerk, S.E. \& Van Velden, C.E (2004).Perception of the clinical competence of newly registered nurses in the North West Provence.Curationis,27(3), 72-84. http://dx.doi.org/10.4102/curationis.v27i3.1003.

[30]MOHSS Ministry of Health and Social Services (2004) Adolescent friendly heath service (AFAS) For Namibia A training manual Windhoek MOHSS

[31]O'Cauaghaint, N. \& Slevin, E. (2003). An investigation of the lived experiences of registered nurses facilitating supernumery nursing student nurses. Education Today, 23, 123-130. http://dx.doi.org/10.1016/S0260-6917(02)00213-7.

[32] Papp, I., Markkanen, M. \& Von Bonssdorff, M. (2003). Clinical environment as a learning environment: student nurses perception concerning learning experiences. Nurse Education Today, 23, 262-268. http://dx.doi.org/10.1016/S0260-6917(02)00185-5.

[33]Polit, N.F., Beck, C.T. \& Hungler, B.P. (2006).Essentials of Nursing Research methods Appraisals and utilizations (6 ${ }^{\text {th }}$ ed.). Lippincott: Philadelphia.

[34]Preceptorship. (2003) Retrieved July 7. 2008 at http://www.nuigalway.ie/nursing/perseptorship.htm

[35]Quinn, F.M. \& Heights.(2007). Principles and practice of nurse education. Cheltenham, U.K.: Nelson Thorn

[36]Rew, L. (2005). Adolescent health.A multidisciplinary approach to theory, research and intervention. University of Texas, Austin, SAGE Publications: Thousand Oak, London, New Delhi.

[37]Saks, M. \& Allsop, J. (2007).Researching Health: Qualitative, Quantitative and Mixed Methods. SAGE Publications: Los Angeles.

[38]Sardo, D.S., Santos, M.R., Kock, M.C., Pires R.M., Machado, P.P. \& Morais, E.E.A. (Undated). Current Development in TechnologyAssisted Education. Available on line Retrieved on 2.6.2008. athttp:/www.foormatex.org/mite2006.

[39]Sardo, D.S., Santos, M.R., Kock, M.C., Pires, R.M., Machado, P.P. \& Morais, E.E.A. (Undated).Condition and factors in nursing. Student Clinical Supervision.Retrieved on 2.6.2008 at www.foormatex.org/mite2005

[40]Sharif, F. \& Masoumi, S. (2005). A Qualitative Study of Nursing Students' Experience of clinical Practice: The Cochrane Library.
[41]Shin, K.R. (2000). The meaning of clinical experiences of Korean nursing students.Journal of Nursing Education, 39(6), 259-265.

[42] Shuttleworth, M. (2008). What is a Paradigm? Retrieved June 2013 from Experiment Resources: http://www.experimentresources.com/what-is-a-paradigm.html.

[43]Todd, C. \& O'Connor, J. (2005).Clinical Supervision. In N. Skinnerf, A.M., Roche \& J. O'Connor, tice Strategies: (Y. Pollard \& Todd (Eds). Workforce Development Tips - Theory into practice Strategies - A resource kit for the alcohol and other drugs field. National Centre for the Education and Training on Addiction (NCETA). Flinders University: Addaillle, Australia $196-181$.

[44]Watson E., 2011 System approach workbook for health education and program planning Sudburg: Jones \&Bartlett.

[45]Willis, J. \& Ricketts, M. (2004).Continuous learning cycle.Executive Edge. 